\title{
Interventions, Collaborative Relationships and Burnout: Special Educators, Speech and Occupational Therapists Perspectives of Speech Disorders
}

\author{
Garyfalia Charitaki, Vasiliki Koutsikou, Spiridon Soulis Spyridon, Alexander-Stamatios Antoniou \\ Faculty of Primary Education, University of Athens, Athens, Greece \\ Email: lcharitaki@hotmail.com
}

How to cite this paper: Charitaki, G., Koutsikou, V., Spyridon, S. S., \& Antoniou, A.-S. (2018). Interventions, Collaborative Relationships and Burnout: Special Educators, Speech and Occupational Therapists Perspectives of Speech Disorders. Psychology, 9, 679-690.

https://doi.org/10.4236/psych.2018.94042

Received: February 21, 2018

Accepted: April 15, 2018

Published: April 18, 2018

Copyright $\odot 2018$ by authors and Scientific Research Publishing Inc. This work is licensed under the Creative Commons Attribution International License (CC BY 4.0).

http://creativecommons.org/licenses/by/4.0/ Open Access

\begin{abstract}
This research aims to investigate special educators' and therapists' perceptions for Speech Disorders. Coping with speech disorders, cooperative relationships and burnout is posed at the focal point of the research. The sample consisted of five speech therapists, five special educators, five occupational therapists and an interdisciplinary group. Qualitative analysis showed no significant diversification which poses at common treatment for Speech Disorders among specialists and highlights the significance of collaboration. Also, high levels of Professional Well-Being were recorded. The main drawback was related to failure of implementing frequent meetings due to lack of time. Finally, results are discussed in terms of organization and improvement of Special Education structures.
\end{abstract}

\section{Keywords}

Speech Disorders, Intervention, Collaborative Relationships, Burnout, Special Educators, Speech and Occupational Therapists

\section{Introduction}

Children's oral speech has its typical starting point between the $12^{\text {th }}$ and $15^{\text {th }}$ month. Phonological, syntactical and grammatical inadequacies are often noted in children with speech disorders even though they may develop speech at expected age. Primatological deficits directly linked to communication are also presented in children with Asperger. An immediate effect is directly linked to the elimination of the use of oral speech for the expression of basic needs and 
interests.

An additional difficulty is directly linked to the determination of treatment and intervention needs in children who are diagnosed with speech disorders which do not co-exist with other disabilities. This is the basic reason which highlights the importance of the role of Special Educators (Antoniou, Geralexis, \& Charitaki, 2017) and Therapists. Professionals may experience feelings of anxiety due to their responsibility for teaching and implementing interventions.

Burnout has been thoroughly studied in terms of its components and different job aspects (Jackson, Schwab, \& Schuler, 1986). Nevertheless, the research focuses on professionals working with children with intellectual disability and on primary education teachers. Thus, there is a shortage of research data related to burnout in Special Educators and Professionals working with children with special educational needs in general.

\section{Theoretical Background}

Oral speech is the mechanism that connects the production and perception of phonemes. It is based on the coordination of breathing, vocalization resonance and articulation. Children with speech disorders have difficulties either in speech production, or in coordinating systems (Dodd, 1996).

Communication is divided into verbal and non-verbal. Verbal communication consists of verbal symbols, such as words and sentences, while non-verbal communication is performed with expression, gestures and physical and emotional behavior of the communicating person. The communication process consists of the transmitter, the symbols, the communication medium and the receiver (Porpodas, 1999; Barakou, 2014).

According to neurological approaches, the child's speech represents a fundamental function in order for the child to be able to communicate, think and learn. Furthermore, the use of speech contributes to the child's emotional development and socialization (Schieffelin \& Ochs, 1986). On the other hand, according to the linguistic approach, communication implies the ability of using language in terms of a linguistic, physical and social context (Kati, 2000; Porpodas, 2003).

Conquest of speech depends on genetic and environmental factors. Specifically, speech develops within the child's first three years of life, and is influenced by communication stimuli such as sounds and images. Infants start to communicate before talking through crying, smiling and producing sounds. However, the study of speech disorders is based on biological and organic factors, even though emotional and social factors are also considered as a possible basis for speech disorders. The developed and coordinated operation of neurodevelopmental, stomatologic and vocal functions is necessary for the comprehension of oral speech (Karzia, 2011).

According to ICD-10 diagnostic criterion, speech disorders are classified into 6 categories. Children who misuse phonemes but have a typical level of linguistic 
skills are classified in those 6 categories. Furthermore, children with a language expression disorder may face difficulties in oral speech, but they can normally understand the language. The ability to understand language is diminished in children with perceptual language disorder and this often presents problems in phonemics production. Another category includes the Landou-Kleflner syndrome which refers to acquired aphasia accompanied by epilepsy. Within the "other developmental speech disorders" category, lisp is included. The final category refers to unspecified disorders with significant developmental damages. There is also an additional category which refers to other behavioral and emotional disorders that usually begin in childhood and adolescence (e.g. stutter) (Iliaki, 2013; Hitoglou-Antoniadou, 2000). According to DSM-IV, communication disorders are divided into 5 categories: linguistic expression disorder, language perception and expression mixed disorder, phonological disorder, stutter and unspecified communication disorder (Iliaki, 2013).

Children with Speech Disorders experience isolation quite often. Their relationships with peers are limited and they often get along with adults (Papalexopoulou \& Charitaki, 2017). Speech disorders and learning difficulties in general occur from pre-school age. Thus, it is very important to detect and deal with difficulties from the early years of childhood. The term "early intervention" refers to the specialists' involvement both in confronting the difficulties and in the child's educational and social development. Early intervention is applied to children up to 8 years old, through medical, social and educational services (Kirk et al., 2011; Hemmeter, Santos, \& Otrosky, 2008).

For the education of children with speech disorders, the special educator's role is very important, as it can be characterized as multifaceted and multiform. Generally, special educator's tasks include direct teaching, and the provision of information and guidance. Moreover, tasks also include counseling and support for the child and the parents, and the interconnection of the school with the local community (Persidou, 2010; Kypriotaki, 2003). Since he/she is responsible for the development of personalized educational programs, the special educators' role is pedagogic-didactic, where the aim of the personalized educational programs is to teach cognitive and basic skills. Furthermore, the special educator is responsible for the child's needs evaluation in order to incorporate feedback and readjust the teaching objectives. For general education teachers' information and support, the special education teacher performs scheduled and non-training meetings with colleagues and auxiliary staff (Wasburn-Moses, 2005; York-Barr et al., 2005). In respect of cooperation with local community sectors, the special educator takes responsibility for the coordination of the support structure's implementation by programming necessary collaborations according to the intervention program, and by setting down the results (Haroupias, 2005).

Special education, depending on the child's abilities, is aimed towards their inclusion into the educational system. To achieve this goal, the speech therapist also has an important role. Specifically, his/her role is to develop and contribute 
to phonological awareness, reading, comprehension and discrimination of visual and acoustic stimuli (Polichroni, 2011). Working and collaborating with other professionals is also very important, because one intervention complements the other. Regarding pedagogues, there should be cooperation to create joined educational objectives in relation to the child's personalized needs. In order to have an effective cooperative intervention and in addition to dealing with language disorders, the speech therapist should have a more extensive knowledge relying not only on the medical model. On the other hand, one of the most important problems that arise in cooperative relationships is the hierarchy and authority's relations, which impede the multidisciplinary collaboration's implementation in practice (Polchronopoulou, 2004; Panteliadou, 2011). The "Interdisciplinary approach" refers to the cooperation of different professionals' in order to educate and confront the child's special educational needs problems. This approach should be taken at all stages of special education from diagnosis to vocational rehabilitation (Alahiotis, 2004).

Research has suggested that the cooperation of general and special educators is minimal. Participants have indicated that they need to participate and work with the teachers, as they have the same responsibility for an effective co-education. The literature also indicates that in order to create a supportive environment in the classroom with children with special educational needs the cooperation of professionals from different specialties is essential. Such collaboration is achieved by the individuals' interaction through communication, negotiation, co-ordination and information sharing (McLaughlin, 2002).

A study by Koureta (2015) aimed to investigate the speech therapist's role in children with learning disabilities, according to secondary school teachers' opinions. The results showed that the speech therapist's role is considered to be more therapeutic than supportive. Specifically, the speech therapist's role is mainly concerned with the learning difficulties' diagnosis, evaluation, intervention, rehabilitation and prevention as well as his/her collaboration with the interdisciplinary team. Since the early diagnosis and confrontation of difficulties leads to better prognosis and prevention of adverse effects on the child, the speech therapists' role is very important (Koureta, 2015).

Research by Iliaki (2013) focused on the pre-school teachers' views of speech disorders and on cooperative relations. According to the results of this survey, kindergarten participants expressed the view that there is no effective collaboration with speech therapists. They characterized their cooperation as "typical" since it is only implemented by telephone, in order to provide information about the child's progress. The lack of institutionality and the problems that arise from bureaucratic procedures were also mentioned. All of the above represent reasons as to why the cooperation is discouraged. More specifically, pre-school educators underline the significance of speech therapy, but they find difficulty in implementing the cooperation among educators and therapists.

The reasons for professional burnout may be divided into three categories. 
The first refers to the individual category which results from the differences that emerge between a person's expectations and reality in the workplace. As a result, the individual may apply the wrong confrontation and organization strategies. The second refers to the interpersonal category, which includes demanding workplaces. The final category refers to the organizational category which includes work requirements, lack of autonomy, lack of reward and conflicts (Vassos \& Nankervis, 2012). Research has demonstrated that the type of difficulties faced by a student affects the burnout of the person who is working with him/her. Mental deficiency professionals experienced professional burnout at a higher level than those working with hearing impaired people. To conclude, in Lavian's (2012) survey, teachers seemed to have a higher sense of anxiety when the organizational atmosphere in the workplace was not supportive.

\section{Method}

\subsection{Research Design}

The focal point of this research is posed at Interventions, Collaborative Relationships and Burnout as impressed through Special Educators, Speech and Occupational Therapists perspectives. For the aforementioned purpose, a qualitative approach was chosen.

\subsection{Sample-Participants}

Purposeful Sampling was chosen for this research in order to include cases of participants on preconceived criteria, such as experience in implementing intervention programs aimed at children with Speech Disorders. The sample consisted of 5 special educators, 5 speech therapists, 5 occupational therapists and an interdisciplinary team.

\subsection{Research Tools}

For the purpose of data collection, the semi-structured interview procedure was selected. The list of interview questions was designed according to Iliaki (2013) and previous work in the field. The semi-structured interview was conducted with the 5 special educators, the 5 speech therapists and the 5 occupational therapists. The interview consisted of 5 parts: 1) questions about gender, age and years of work, 2) questions about personal factors, 3) questions in relation to organizational factors, 4) questions regarding management mode and 5) questions regarding cooperation among the specialties. Moreover, an unstructured observation was conducted across an interdisciplinary group consisting of 3 specialists ( 1 special educator, 1 speech therapist, 1 occupational therapist).

\section{Results}

There were no significant differences identified across the specialists in relation to feelings of burnout. In general, special educators seemed to be satisfied and were positive about their work. However, in some cases they reported feelings of 
tiredness and exhaustion. They expressed their attempts to deal with this in a creative manner, by being motivated by the joy and satisfaction that they feel when their intervention is effective. The feedback that professionals receive from the structures at their workplace seemed to play an essential role in terms of level of burnout. The qualitative analysis showed a clear indication of the importance of cooperation both in the effectiveness of intervention programs and professional development. The lack of material and space within the organization appeared to be a suppressive factor for effective intervention. Some participants argued that the state is responsible for this situation, rather than the individual within the structure.

Special educators, speech therapists and occupational therapists reported being very satisfied with the collaboration with other members of staff. Many felt that they experienced friendly relationships and that there was a teamwork climate. A significant drawback, which was recorded, was related to failure of implementing frequent meetings due to lack of time. The majority of speech therapists suggested that more materials and a better organization of the environment were required in order to improve the working environment. The number of children in the classroom was also reported as a problem by special educators. Occupational therapists were generally satisfied with materials and staff benefits, referring only to increased coordination and frequent meetings with the disciplinary team as a desired change that could be incorporated. Providing updates through seminars for professionals and for parents was also considered essential.

Regarding the research question in relation to dealing with speech disorders, the findings indicate that all three specialties follow a common line based primarily on evaluation and then working with parents. To address children's speech disorders, professionals rely heavily on the help from the disciplinary team.

The final research question referred to collaboration of the interdisciplinary team. From the interviews it appeared that each specialty has its own role and limits. Everyone is responsible for his/her own part in dealing with the disorder, but this is always preceded by a discussion between the members of the interdisciplinary team. Such discussion incorporates the key objectives and the common line that must be followed. Although sometimes minor problems may occur, there appears to be a very positive cooperative climate. Through discussion and understanding, any problems that arise can be resolved thus having a positive impact on the child.

Finally, an ideal interdisciplinary team is characterized by a group, consisting of all members of the treatment team engaging in frequent meetings with the aim of providing continuous information and achieving effective cooperation. For all specialists, an ideal interdisciplinary team includes a psychologist, a speech therapist, a special educator, an occupational therapist and a child psychiatrist. Special educators also referred to the inclusion of a social worker and speech therapists referred to the inclusion of a psychotherapist. Lastly, speech 
therapists also noted the need of a coordinator who would be responsible for collaborations with doctors and schools.

In the interdisciplinary team's observation, the researcher attended three meetings and recorded strategies for treatment and cooperation between a speech therapist, a special educator who was also a psychologist, and an occupational therapist.

In this study methods for managing an 8-year-old girl with Speech Disorder were observed. $\mathrm{Z}$ attends the 2 nd class of Primary School, with parallel support. She implements an intervention program, which includes speech therapy twice a week, occupational therapy once a week, special education twice a week, and counseling once every second week. The speech therapist focused on vocabulary development and communication skills. The occupational therapist worked on sensory difficulties. The special educator focuses on learning academic skills such as writing, reading and reading. Sometimes she participates in a group which includes two students.

The collaboration of the interdisciplinary team was very good and each member was supportive towards the other. The problem faced by the team in this case was Z's mother. Her mother has a tendency to create problems among the therapists. For example, the mother complains to the speech therapist that the special educator argued that the child cannot be improved in a specific area, while it appeared that the special educator had never implied this. Finally, communication with school teachers was suggested since the mother claimed that the school teachers do not behave properly towards $\mathrm{Z}$ and that they do not help her.

\section{Discussion}

The results of the survey generally show that speech therapists', special educators' and occupational therapists' management approaches do not differ greatly when confronting speech disorders. As mentioned by the participants, the first necessary step is the evaluation through the child's history and through each test used by each specialty according to its own criteria. The first objective of the professionals is to identify the child's abilities and difficulties in order to set short- and long-term goals. According to the literature, effective intervention begins with evaluation and the goals that arise from each child's necessity (Persidou, 2010; Polichroni, 2011). For the creation of treatment programs for children with speech disorders, the participation of a speech therapist, and often a special educator is necessary, but it is not always necessary to include an occupational therapist. In an intervention program an occupational therapist may not be necessary because speech disorders by themselves do not cause difficulties in movement. However, there are cases where speech disorders are the result of another disorder, such as autism that can be accompanied with difficulties in chewing and swallowing and generally in the way of thinking in order for a movement to be conducted (Panteliadou, 2011; Polichroni, 2011).

Family perceptions also influence the way in which specialists intervene, be- 
cause the start of the implementation of the treatment program depends on acceptance and recognition of the child's difficulties by the parents. So it seems that a primary factor for an effective intervention is the parents' cooperation. Consulting parents on dealing with disappointment and pessimistic views for their children's attainments is a demanding area and prerequisites careful handling from Psychologists (Wasburn-Moses, 2005). According to Iliaki (2013), kindergartens believe that parents' involvement in the interdisciplinary team is negative, which is not at all consistent with the beliefs of the individuals participating in this research.

Speech disorders affect a child's behavior, but speech therapists, special educators and occupational therapists have argued that they chose to engage in special education because they think that those children have many abilities. The child's profile appears to be influenced by social and psychological constraints (Koumpias \& Foustana, 2003; Tzouriadou \& Barbas, 2001). Other inhibitory factors may come from the state, from the education system and from agencies where special education practitioners are working. In other studies, great expectations have been put forward by speech therapists leading to the notion that speech therapists are exclusively responsible for dealing with speech disorders. This can set aside other professionals, and the sector should demonstrate equal trust towards special educators and occupational therapists (Iliaki, 2013). It is worth noting, that professionals' confrontation appears to differ between the private and the public sector. Due to many shortages in the public sector, it is more difficult to put effective structures in place.

Regarding the feelings of professionals who work with children with special needs, these are generally positive. The vast majority of participants stressed that despite the great responsibility that they have for the children, they gain a lot of experience and developed their effectiveness in implementing intervention programs. Most participants said that they find ways to manage tiredness in the workplace, and none of them reported holding a passive attitude. In particular, few participants mentioned that they use breaks as relaxation aids, whilst other utilize their interest in activities. It has been found that high burnout rates are associated with passive attitudes, while lower rates are experienced by people who follow more active and practical strategies (Vassos \& Nankervis, 2012). In this study, it was expected that most participants would have high burnout rates, but this was not confirmed (Maslach, Schaufeli, \& Leiter, 2001). Also, research has identified that the conflict of personal and professional life is associated with high feelings of anxiety and exhaustion (Devereux et al., 2009; Vassos \& Nankervis, 2012). However, in this sample it appeared that professionals manage to separate their personal and professional lives. While they may be dealing with a personal issue, they try to ensure that this does not affect their performance and that it is not perceived by children and parents.

The interdisciplinary team cooperation between members was positive and the existence of friendly relations was mentioned. The results of Koureta's 
(2015) research have led to the view that the role of the speech therapist is purely therapeutic. The current research does not agree with this finding since both special educators and occupational therapists have characterized the speech therapist's work and his/her role as a supportive one. The majority of participants reported that members of the interdisciplinary team follow a common line and few argued that there are tensions and disagreements. In general, their cooperation is positive and is carried out through discussions (Tzouriadou, 2001; Alahiotis, 2004). The only changes highlighted by special educational professionals referred to the need for implementation of material enrichment, space organization and treatment programs. Finally, all of the above can be effectively carried out in the presence of an ideal interdisciplinary team consisting of a psychologist, a speech therapist, a special educator, an occupational therapist and child psychiatrist, and in some cases the inclusion of social workers and physiotherapists (Alahiotis, 2004).

\section{Conclusion}

The most effective form of education for children with special educational needs and children with typical development is inclusion (Avramidis \& Dialektakki, 2010). In Greece, general education teachers argue that children with special educational needs should attend special education schools (Zoniou-Sideri \& Vlachou, 2006). However, in order to cope with the difficulties encountered by a child with speech disorders and to make it easier for him/her to function in everyday life, the contribution of occupational therapist, speech therapist and special educator is essential (DfES, 2004; Alahiotis, 2004).

It is very important for all members of the interdisciplinary team to understand and appreciate the role of all of the people involved. In order to obtain a more comprehensive view of the child's needs, there should be cooperation between the interdisciplinary team and the children. Interaction of people with different specialties also contributes to the personal professional development of each specialist. Effective cooperation consists of discussions through which goals are set for the child and these are redefined at regular intervals. However, the most frequent obstacle to successful co-operation is hierarchy and power relations (Tzouriadou, 2001).

The goal of the interdisciplinary team is to identify the child's abilities and difficulties and then to set short-term and long-term goals. According to the literature, an effective intervention begins with evaluation and then proceeds to setting goals that arise from the necessity of each child (Persidou, 2010; Polichroni, 2011). During the intervention process, the family has an important role as they first need to accept and understand the child's difficulties in order to be cooperative with the therapists. For effective intervention, parents' cooperation is not only desirable but it is necessary (Wasburn-Moses, 2005). In addition to the fact that parents need to recognize and accept the child's difficulties, therapists should also recognize the parents' potential and weaknesses. 


\section{Study Limitations \& Future Propositions}

From the participants' responses regarding personal and organizational factors, it appears that professionals working with special education children do not have high rates of burnout as expected. Generally, there is a sense of fatigue, but this does not interfere with the positive emotions that they gain from an effective intervention. However, the lack of organization of the structure within which they work can cause problems. The discrepancy regarding the results of this research compared with the findings reported in the literature may be due to the fact that therapists use positive perceptions as a protective factor in order to avoid burnout or because during the interviews they provided answers that they considered to be socially acceptable.

However, the current research is important because it has attempted to obtain a more holistic view of interdisciplinary cooperation rather than focusing on one specialty as presented in previous studies. In particular, the methodological triangulation that was conducted has the advantage of providing the opportunity for a multi-faceted examination in order to obtain the views of professionals regarding how to handle speech disorders, burnout and collaboration. Also, the results of this research can be considered in terms of organization and improvement of Special Education structures.

The limitations presented in this study, include the fact that participants originated only from Athens. This limits the generalization of results in the province. Also, there was no correlation with demographics, for example, it is unclear whether the results may be related to age, gender, etc. A further limitation is that the interviews and observations took place with the presence of the researcher and as such, participants may have provided socially acceptable answers in order to present a better and ideal reality.

\section{References}

Alahiotis, S. (2004). For a Modern Education System: Cross-Border and Flexible Zone Change Education and Upgrade Quality Education. http://www.pi-schools.gr/programs/depps/

Antoniou, A. S., Geralexis, I., \& Charitaki, G. (2017). Special Educators' Teaching Self-Efficacy Determination: A Quantitative Approach. Psychology, 8, 1642-1656. https://doi.org/10.4236/psych.2017.811108

Avramidis, H., \& Dialektaki, K. (2010). Changing Teachers' Attitudes towards Integration: From Ideology of Authenticity to the Authentic Implementation of Inclusive Education. In N. Polemikos, M. Kaila, E. Theodoropoulou, \& B. Strogylos (Eds.), Education of Children with Special Needs. A Multi-Prism Approach. Athens: Pedio.

Barakou, X. (2014). Speech and Communication Problems in Children with Diffuse Developmental Disorders: Case Study with Child Education with High Functionality Autism. Ioannina: TEI of Epirus.

Devereux, J., Hastings, R., \& Noone, S. (2009). Staff Stress and Burnout in Intellectual Disability Services: Work Stress Theory and Its Application. Journal of Applied Research in Intellectual Disabilities, 22, 561-573.

DfES (Department for Education and Skills) (2004). Primary National Strategy: Addi- 
tional Approaches for Children with Severe and/or Complex Needs. Nottingham: DfES Publications.

Dodd, B. (1996). Do All Speech-Disordered Children Have Motor Deficits? Clinical Linguistics \& Phonetics, 10, 77-101. https://doi.org/10.3109/02699209608985164

Haroupias, A. (2005). Procedures for the Establishment and First Functioning of the Integration Section.

Hemmeter, M. L., Santos, R. M., \& Ostrosky, M. M. (2008). Preparing Early Childhood Educators to Address Young Children's Social-Emotional Development and Challenging Behavior. Journal of Early Intervention, 30, 321-340.

https://doi.org/10.1177/1053815108320900

Hitoglou-Antoniadou, A. (2000). Autism-Hope. Sallonika: University Studio Press。

Iliaki, X. (2013). Early Childhood Educators' Perceptions for Speech Disorders: Perceptions, Interventions and Cooperative Relationships. Athens: National and Kapodistrian University of Athens.

Jackson, S. E., Schwab, R. L., \& Schuler, R. S. (1986). Toward an Understanding of the Burnout Phenomenon. Journal of Applied Psychology, 71, 630-640. https://doi.org/10.1037/0021-9010.71.4.630

Karzia, A. (2011). Speech and Speech Disorders. A Chronic Disorder or a Simple Delay in Communication. Small Diagnostic and Therapeutic Steps. Thessalonica: Metheksis.

Kati, D. (2000). Child's Language and Communication. Athens: Odysseus.

Kirk, J., Gallagher, J., Coleman, M. R., \& Anastasiou N. (2011). Educating Exceptional Children. US: Wadsworth.

Koumpias, E., \& Foustana, A. (2003). Self-Segregation of School-Age Children with Speech and Behavioral Problems. In Ativa: 9th Conference of the Panhellenic Association of Speech Therapists.

Koureta, M. (2015). Views and Attitudes of Secondary Education Teachers on the Role of Logotherapist in Children with Learning Disabilities. Kalamata: School of Health and Welfare Professions, Department of Speech Therapy.

Kypriotaki, M. (2003). Autistic Children and Their Treatment (3rd ed.). Heraklion: Kypriotaki.

Lavian, R. H. (2012). The Impact of Organizational Climate on Burnout among Homeroom Teachers and Special Education Teachers (Full Classes/Individual Pupils) in Mainstream Schools. Teachers and Teaching: Theory and Practice, 18, 233-247. https://doi.org/10.1080/13540602.2012.632272

Maslach, C., Schaufeli, W. B., \& Leiter, M. P. (2001). Job Burnout. Annual Review of Psychology, 52, 397-422. https://doi.org/10.1146/annurev.psych.52.1.397

McLaughlin, M. J. (2002). Examining Special and General Education Collaborative Practices in Exemplary Schools. Journal of Educational and Psychological Consultation, 13, 279-283.

Panteliadou, S. (2011). Learning Difficulties and Educational Practice: What and Why. Athens: Pedio.

Papalexopoulou, A., \& Charitaki, G. (2017). Social Skills in Children with Specific Language Impairment: Occupational and Speech Therapists' Perceptions. Asian Journal of Applied Science and Technology, 1, 192-198. http://ajast.net/data/uploads/50.pdf

Persidou, A. (2010). The Special Educator in the Implementation of Integration: Exploring the Advisory Dimension of His Role. Thesalonika: Aristotle University of Sallonika.

Polchronopoulou, S. (2004). From School Life to Productive Process and Autonomous 
Living: Criteria for Smooth Transfer. Science and Education, 4, 10-20.

Polichroni, F. (2011). Special Learning Difficulties. Athens: Pedio.

Porpodas, K. (1999). Cognitive Psychology: Language Psychology-Problem Solving (Vol. 2). Athens: University of Patras.

Porpodas, K. (2003). Learning and Its Difficulties (Cognitive Approach). Patras: University of Patras.

Schieffelin, B. B., \& Ochs, E. (1986). Language Socialization. Annual Review of Anthropology, 15, 163-191. https://doi.org/10.1146/annurev.an.15.100186.001115

Tzouriadou, M. (2001). Early Intervention, Modern Trends and Prospects. Sallonika: Promitheus.

Tzouriadou, M., \& Barbas, G. (2001). Children with Special Needs in Pre-School Education: The Views of Early Childhood Educators. In M. Tzouriadou (Ed.), Early Intervention: Modern Trends and Prospects. Sallonika: Promitheus.

Vassos, M. V., \& Nankervis, K. L. (2012). Investigating the Importance of Various Individual, Interpersonal, Organisational and Demographic Variables When Predicting Job Burnout in Disability Support Workers. Research in Developmental Disabilities, 33, 1780-1791. https://doi.org/10.1016/j.ridd.2012.04.016

Wasburn-Moses, L. (2005). Roles and Responsibilities of Secondary Special Education Teacher in Ann Age of Reform. Remedial and Special Education, 26, 151-158.

York-Barr, J., Sommerness, J., Duke, K., \& Ghere, G. (2005). Special Educators in Inclusive Education Programmes Reframing Their Work as Teacher Leadership. International Journal of Inclusive Education, 9, 193-215.

Zoniou-Sideri, A., \& Vlachou, A. (2006). Greek Teachers' Belief Systems about Disability and Inclusive Education. International Journal of Inclusive Education, 10, 379-394. 